\title{
DIALÉTICA E O JOGO DOS CONTRÁRIOS
}

Dialectic and the game of contrary

Michele Borges Heldt*

Resumo: Na dialética, a contradição mostra-se como sendo de suma importância, na medida em que a mesma é entendida como a força propulsora de todo o movimento dialético, e onde a primeira forma de contingência já se faria presente junto do próprio ser, na medida em que algo, mesmo existente, pode sempre não existir. Entretanto, de acordo com CirneLima, a transformação gradual de contingência em necessidade que ocorre na dialética hegeliana, em sua última consequência, conduziria à eliminação do sujeito individual.

Nesse sentido, o mesmo propõe que a ideia absoluta não seja entendida como um "sernecessário", mas sim como um "dever-ser", que permitiria a possibilidade de que as coisas que são determinadas de um modo, sob certas circunstâncias, pudessem ser de outra maneira.

Palavras-chave: Dialética. Contradição. "SerNecessário". "Dever-Ser".

\begin{abstract}
At dialectic, contradiction shows as being of very important, to the extent that seen is as the driving force of all the dialectical movement, and where the first form of contingency already do this with the self, insofar that something even existing, may always not exist. However, according to CirneLima, the gradual transformation of contingency into necessity that occurs in the hegelian dialectic, in its last consequence, lead to the elimination of the individual subject.

Accordingly, it proposes that the absolute idea is not understood as a "be-necessary", but rather as a "must-be", which would allow the possibility that things are a certain way, under certain circumstances, could be otherwise.
\end{abstract}

Keywords: Dialectic. Contradiction. "BeNecessary". "Must-Be". * Mestranda do Programa de Pós-graduação em Filosofia da Pontifícia Universidade Católica do Rio
Grande do Sul (PUCRS). Bolsista Próbolsas/PUCRS. Contato: heldt.michele @ hotmail.com

\begin{tabular}{|c|c|c|c|c|c|}
\hline intuitio & $\begin{array}{c}\text { ISSN } \\
1983-4012\end{array}$ & Porto Alegre & Vol.7 $-\mathrm{N}^{\mathrm{o}} .2$ & $\begin{array}{c}\text { Novembro } \\
2014\end{array}$ & p. 184-196 \\
\hline
\end{tabular}




\section{A contradição na filosofia analítica}

Primeiramente, Cirne-Lima considera que o estudo sobre a contradição, dentro do sistema dialético, é especialmente relevante porque a contradição seria a força propulsora de todo movimento dialético.

Em segundo lugar, afirma que, no decorrer da história da filosofia, os filósofos teriam se dividido em dois grandes grupos, a saber: os dialéticos, (seguidores do pensamento platônico), e os analíticos, (defensores de Aristóteles, que apoiam a ideia de que a única maneira de fazer ciência do pensamento seria através da análise) e essa divisão teria começado, principalmente, por conta da contradição.

Na filosofia analítica, o Princípio de Não-Contradição é a sentença que afirma que é impossível que uma proposição seja verdadeira quando ela contradiz a si mesma, pois duas proposições contraditoriamente opostas não poderiam ser simultaneamente verdadeiras, nem simultaneamente falsas. Se uma é verdadeira, necessariamente a outra teria de ser falsa.

Para Cirne-Lima, teria sido Hegel que, de forma mais explícita, através da revitalização da tradição dialética, teria se contraposto ao Princípio de Não-Contradição de Aristóteles, visto que Hegel considerava que todas as coisas seriam em si mesmas contraditórias.

Nesse sentido, os termos "ao mesmo tempo" e "sob o mesmo aspecto" introduzidos no Princípio de Não-Contradição, eliminariam somente parcialmente o problema da contradição, conforme exposto na citação abaixo:

Tempos diversos não implicam, ao que parece, dialética nenhuma. Mas não se trata somente de diversos momentos do tempo[...] há perguntas que, em determinadas circunstâncias, devem ser respondidas, em verdade, por um "sim e não" ao mesmo tempo. À pergunta, se a rosa é vermelha, deve ser respondido "sim e não", pois se faz necessária uma ulterior determinação dos aspectos sob os quais ela é vermelha e dos aspectos sob os quais ela não é vermelha ${ }^{1}$.

O problema lógico que surge aqui seria referente à natureza do Princípio de NãoContradição, conforme será abordado na sequência. A validade universal do Princípio de NãoContradição seria afirmada, a princípio, com referência ao problema da indeterminação, através de uma resposta exata e final: se há falta de nitidez, se há necessidade de determinação posterior, então o predicado não estaria suficientemente apto para exercer sua função.

Entretanto, ao recolocar um antigo problema, Cirne-Lima coloca em dúvida novamente a validade universal dessa teoria, conforme segue: "Poder ser e poder não ser, juntos e

\footnotetext{
${ }^{1}$ CIRNE-LIMA. Sobre a Contradição. Porto Alegre: Edipucrs, 2a edição, 1996, p. 16.
}

\begin{tabular}{|c|c|l|l|c|c|}
\hline intuitio & $\begin{array}{c}\text { ISSN } \\
1983-4012\end{array}$ & Porto Alegre & Vol.7 $-\mathrm{N}^{\mathrm{o}} .2$ & $\begin{array}{c}\text { Novembro } \\
2014\end{array}$ & p. 184-196 \\
\hline
\end{tabular}


simultâneos, constituem a definição de contingência. Contingência é aquela indiferença do ser aí existente, que, mesmo existente, pode sempre não existir"2.

Ao investigar o conceito de contingência, observa-se que a mesma exige que algo, ao mesmo tempo e sem deixar de ser a mesma coisa, possa ou não existir. Assim, a contradição e a dialética (que inicialmente haviam sido excluídas do contingente existente), retornariam quando os momentos da contingência e da existência são evidenciados, onde a essência (poder ser e poder também não ser) e a existência (ser e enquanto ser não poder não ser) seriam dois princípios constitutivos da unidade concreta do existente contingente. Nas palavras de CirneLima “[...] eles são dois princípios diferentes um do outro, mas são compatíveis um com o outro e, juntos, compõem e constituem o ser concreto"3.

Existem proposições que, para serem declaradas verdadeiras ou falsas, necessitam ser confirmadas por meio da experiência. Conforme se sabe, na filosofia essas proposições são chamadas de a posteriori, enquanto que as proposições a priori são aquelas cuja verdade ou falsidade podem ser conhecidas independentemente da experiência sensível.

As proposições a priori são tidas como verdadeiras ou falsas por sua estrutura interna, e essa, segundo Cirne-Lima, seria uma repetição lógico-semântica visto que, ao se repetir, ela diria apenas aquilo que já foi dito. A verdade ou falsidade dessas proposições recolocadas se definiria conforme a verdade ou a falsidade da proposição primitiva.

Nesse ponto, conforme Cirne-Lima, ocorreria uma mudança: ao ser reduplicada, a proposição que era simples se tornaria uma proposição complexa (composta por duas proposições simples), onde a verdade de "p" implicaria a verdade de "p". Dessa implicação material surgiria a implicação formal, e seria através desta que todos os operadores lógicos posteriores seriam definidos.

Entretanto, existem proposições que não são nem a priori e nem a posteriori, e que, ao serem ditas, entram em contradição consigo mesmas, como no exemplo dado por Cirne-Lima, onde, ao dizer em voz alta que não estou falando: o ato de falar contradiz imediatamente o conteúdo falado.

Sob esse prisma, faz-se necessário um retorno ao sentido aristotélico da expressão 'impossível' utilizada na formação do Princípio de Não-Contradição. "É impossível, significa aqui: o ato mesmo de dizer " $x$ " exclui a possibilidade, elimina, impossibilita " $x$ ", $[\ldots]$ o adynaton de Aristóteles é aquela impossibilidade pré-semântica que diz que, ao dizer, alguns dizeres de saída e em princípio estão excluídos”".

Em Aristóteles, o sujeito é sempre um indivíduo em sua substancialidade semântica, enquanto que o predicado é sempre o jogo dos contrários, onde, através da predicação, um

\footnotetext{
${ }^{2}$ CIRNE-LIMA. Sobre a Contradição. Porto Alegre: Edipucrs, $2^{\mathrm{a}}$ edição, 1996, p. 24.

${ }^{3}$ CIRNE-LIMA. Sobre a Contradição. Porto Alegre: Edipucrs, $2^{\text {a }}$ edição, 1996, p. 26.

${ }^{4}$ CIRNE-LIMA. Sobre a Contradição. Porto Alegre: Edipucrs, $2^{\mathrm{a}}$ edição, 1996, p. 32.
}

\begin{tabular}{|c|c|l|l|c|c|}
\hline intuitio & $\begin{array}{c}\text { ISSN } \\
1983-4012\end{array}$ & Porto Alegre & Vol.7- $\mathrm{N}^{\circ} .2$ & $\begin{array}{c}\text { Novembro } \\
2014\end{array}$ & p. 184-196 \\
\hline
\end{tabular}


desses contrários é afirmado e o outro extinto. De acordo com essa Primeira Filosofia, estudar sobre o ser como ser implicaria, diretamente, em estudar também sobre os contrários, que seriam os atributos conferidos a ele. Em outras palavras, os atributos seriam os pares de contrários que constituiriam a estrutura lógico-semântica do ser como ser.

Entrementes, esses atributos seriam acidentais porque, se para Aristóteles, quando se pretende significar e dizer algo, isso se refere à substância de algo (e dizer a sua substância significaria atribuir ser a algo e não a um outro) e, considerando que atribuir ser a algo seria o mesmo que não atribuir ser a esse algo, então ele seria algo outro daquilo que ele é. "Assim eles são obrigados a dizer que nada pode ser assim definido e que, portanto, tudo é acidental"5.

Contudo, considerando que a predicação resulta na predicação sobre a essência do ser, se todas as predicações fossem tidas como acidentais, então não existiria nada de primeiro sobre o que predicar. O ser de um objeto seria o ser de um outro, logo, a contradição se estabeleceria tanto na linguagem, como no ser de todas as coisas.

Assim, para manter a lógica do Princípio de Não-Contradição, Aristóteles teria deixado o discurso lógico-semântico de lado e postulado a existência de um mundo imutável por detrás do mundo sensível. Desse modo, o Princípio de Não-Contradição pôde ser mantido, porque esse mundo imutável e eterno existente por detrás da mudança e do movimento asseguraria a identidade das coisas sensíveis. De acordo com essa ideia, somente no primeiro movente imóvel não existiria o jogo dos opostos.

Já em Hegel, o primeiro e o último princípio não seria o não movido, mas sim o automovido.

Conforme já exposto, em Aristóteles, o ato de dizer, algumas vezes, afirmaria a si mesmo: eu falo que estou falando. Existe aí um ato de fala e um conteúdo falado e, nesse caso, os dois significam e afirmam a mesma coisa. Esse conteúdo de fala que se afirma e se reduplica é, nas palavras de Cirne-Lima, uma "tautologia de conteúdo".

A formulação científica das formas mais complexas de tautologia seria objeto da lógica enquanto ciência meramente formal e, dentro dessa lógica, não haveria espaço para a contradição. Entretanto, invertendo agora o primeiro ato de fala e, ao invés de falar "eu falo que estou falando", se colocar "eu falo que não estou falando" (onde o ato é exercido pelo sujeito, enquanto que o conteúdo é que não se está falando), evidentemente aí existe uma contradição.

Nesse sentido, tomando por verdadeiro o ato de fala e considerando que o conteúdo não corresponde aos fatos, aparentemente, a ordem lógica se reestabeleceria. Contudo, como a não contradição se deu em detrimento do conteúdo falado, para manter a verdade do ato da fala, a falsidade desse conteúdo teve de ser afirmada. Assim, segundo Cirne-Lima, não se poderia dizer que a contradição tenha sido totalmente eliminada.

${ }^{5}$ CIRNE-LIMA. Sobre a Contradição. Porto Alegre: Edipucrs, 2a edição, 1996, p. 34.

\begin{tabular}{|c|c|l|l|c|c|}
\hline intuitio & $\begin{array}{c}\text { ISSN } \\
1983-4012\end{array}$ & Porto Alegre & Vol.7- $\mathrm{N}^{\circ} .2$ & $\begin{array}{c}\text { Novembro } \\
2014\end{array}$ & p. 184-196 \\
\hline
\end{tabular}




\section{Distinção de aspectos como forma de superar a contradição}

A contradição foi eliminada na medida em que a forma foi considerada verdadeira enquanto que o conteúdo foi considerado falso, logo, a facticidade do ato de fala se sobrepôs ao conteúdo falado. Assim, pode-se afirmar que a contradição é superada somente se e enquanto pode-se distinguir forma e conteúdo, ato de fala e conteúdo falado. Com isso, entende-se que distinguir seria afirmar a diversidade de aspectos da mesma coisa, "[...] o processo de interação em que alguém fala que não está falando, leva os interlocutores à necessidade lógico-semântica de distinguir aspectos e de dizer que, sendo um verdadeiro, o outro tem que ser falso"

Aí existiriam dois aspectos da mesma coisa, onde, ao se eliminar um deles, se eliminaria também o outro. Nesse caso, poder-se-ia estabelecer uma lógica baseada em dois grandes princípios: o primeiro seria o Princípio da Contradição, onde as contradições de fato existem e devem ser trabalhadas.

Já o segundo seria o Princípio de Não-Contradição, onde, para poder falar e ser entendido, seria preciso distinguir, sempre que surgisse uma contradição, os diferentes aspectos da mesma coisa. Em ambos os casos, essa lógica não permite separar os dois princípios, visto que um não existe sem o outro. Essa impossibilidade de separação dos dois princípios demonstraria que se trata de um processo cuja solução da contradição seria simplesmente o seu desenvolvimento, pois se trataria de uma lógica do próprio movimento do pensar e do falar e, assim, do ser.

Em Hegel, diferentemente de Aristóteles, não existe uma arkhé, pois tudo seria também uma arkhé. Não existiria um primeiro movente imóvel, pois também ele seria movido e movente no equilíbrio da auto movimentação, na qual não haveria o primado de um sobre o outro.

Essa reflexão sobre si mesmo seria a primeira e mais importante forma de duplicação, onde o refletir seria o movimento do mesmo que sai de si para reencontrar-se consigo retornando a si mesmo e onde, na reduplicação positiva, os atos de fala fundamentariam a lógica analítica, enquanto que a lógica dialética seria fundamentada na reduplicação negativa. Em ambos os casos, ocorreria esse movimento de reflexão sobre si mesmo, por isso que se diz que a dialética hegeliana remete à circularidade.

Nesse sentido, Hegel faz uma crítica dizendo que, ao se fazer uma concessão justamente para o primeiro fundante, toda a série de razões posteriores se fundamentaria em algo determinado unicamente pela negação. Logo, estas estariam se baseando em algo totalmente infundado.

${ }^{6}$ CIRNE-LIMA. Sobre a Contradição. Porto Alegre: Edipucrs, 2a edição, 1996, p. 43.

\begin{tabular}{|c|c|l|l|c|c|}
\hline intuitio & $\begin{array}{c}\text { ISSN } \\
1983-4012\end{array}$ & Porto Alegre & Vol.7- $\mathrm{N}^{\circ} .2$ & $\begin{array}{c}\text { Novembro } \\
2014\end{array}$ & p. 184-196 \\
\hline
\end{tabular}


Em suma, o Princípio de Não-Contradição é entendido, primeiramente, como sendo determinante de um movimento que ocorreria nos âmbitos do pensar, do falar e do ser, onde seria evidente que, no falar e no pensar, de fato existem contradições e que, quando elas aparecem, seria preciso trabalhá-las e superá-las por meio da diferenciação de aspectos.

\section{O "dever-ser"}

Nesse caso, o problema consistiria em saber se existe um universal no singular, e se seria possível fazer disso um sistema filosófico, pois, de acordo com Cirne-Lima, o Princípio de Não-Contradição não afirmaria que seria impossível haver contradições, mas somente que não deveriam haver contradições.

Logo, isso não significaria que contra fatos seriam impossíveis de existir, mas somente apontaria para um "dever-ser", que seria uma proposição normativa que seria válida, mas não tão enérgica a ponto de impedir a existência de exceções, conforme explanado na citação abaixo:

[...] uma forma mais fraca de necessidade à maneira daquela que vige na Ética e nos ordenamentos jurídicos, uma necessidade que vige e que é válida, mas que não torna impossíveis contrafatos como ações antiéticas ou delitos. Essa necessidade mais fraca é expressa melhor pelo termo "dever-ser" do que pela palavra "impossível" ou é "necessário". Ser livre de contradição é, de acordo com esse entendimento, algo que deve ser, não algo que é necessário. Essa forma logicamente mais fraca de necessidade é, na verdade - assim continua o raciocínio - a forma mais alta e mais nobre do "ser-necessário"”.

Nesse sentido, o ideal da razão não seria algo meramente regulativo, mas antes como algo constitutivo. Assim, a necessidade do pensar e do ser não seria um ser-necessário, mas sim um dever-ser.

Em Aristóteles, o Princípio de Não-Contradição é tido como o princípio que rege o pensamento e a fala, bem como a sua formulação. Entretanto, no realismo aristotélico, pensar e falar apontariam para uma realidade existente no mundo externo, que seria diferente do pensar e do falar de fato. Seria algo como um Princípio Ontológico de Não- Contradição que valeria, primeiramente, não para o pensar e o falar, mas para a coisa mesma. "Aristóteles introduz o princípio ontológico quando, para fundamentar a lei lógica da não-contradição, aponta o paralelismo existente entre pensar e ser"».

Sob esse aspecto, pode-se afirmar a existência de dois Princípios de Não- Contradição que, embora interligados, deveriam ser distinguidos, porque o primeiro seria uma lei que regeria o pensar e o falar, enquanto que o segundo seria uma lei do próprio ser. $\mathrm{O}$ fato de essas

\footnotetext{
${ }^{7}$ CIRNE-LIMA. Sobre a Contradição. Porto Alegre: Edipucrs, 2 a edição, 1996, p. 57.

${ }^{8}$ CIRNE-LIMA. Sobre a Contradição. Porto Alegre: Edipucrs, $2^{\mathrm{a}}$ edição, 1996, p. 60.
}

\begin{tabular}{|c|c|l|l|c|c|}
\hline intuitio & $\begin{array}{c}\text { ISSN } \\
1983-4012\end{array}$ & Porto Alegre & Vol.7- $\mathrm{N}^{\mathrm{o}} .2$ & $\begin{array}{c}\text { Novembro } \\
2014\end{array}$ & p. 184-196 \\
\hline
\end{tabular}


exceções existirem e de que contradições realmente ocorrem no pensamento e na fala apontaria para a existência de um segundo sentido do Princípio de Não-Contradição, que, segundo CirneLima, não seria tão forte como o primeiro (que, conforme já explicado, diz que não devem haver contradições), mas sim no sentido de que as contradições deveriam ser evitadas. Daí pode-se concluir que existiriam duas versões do Princípio Lógico de Não-Contradição, onde ambas estariam certas, só que uma valeria apenas dentro de certos limites, enquanto que a outra seria oniabrangente e teria validade ilimitada.

Ainda segundo Cirne-Lima, a primeira versão do Princípio de Não-Contradição (que afirma que contradições são impossíveis) seria uma versão estreita, que teria validade somente em campos limitados como, por exemplo, na Lógica e na Matemática.

Já a segunda versão, afirmaria apenas que não deveriam haver contradições no pensar e no falar, mesmo que vez ou outra elas ocorram. Sendo assim, pensar e falar teriam uma ordem que, em princípio, deveria ser, mas que nem sempre imediatamente existiria e ou estaria efetivada. A racionalidade do processo de constituição do pensamento e da fala consistiria no exercício de formulação lógica, ou seja, de superação das contradições existentes, e somente assim se poderia compreender as variadas formas das coisas que estariam em movimento.

De acordo com Cirne-Lima, os opostos, que no início apareciam em oposição excludente, seriam agora considerados aspectos parciais e conciliáveis do mesmo sujeito. Esses aspectos parciais continuariam sendo opostos (uma vez que um negaria e excluiria o outro), mas se tratariam de aspectos parciais inerentes ao mesmo sujeito. Seria a unidade na qual já estariam superados e guardados, tanto um aspecto, como o outro.

Os predicados que antes se repeliam agora se congregam na unidade dinâmica de um sujeito que é uno, mas logicamente diferenciado. Esta unidade do sujeito não é mais o repouso em si mesmo de uma identidade igual a si própria, mas a tensão centrífuga de aspectos parciais que, enquanto predicados sintáticos, eram contraditórios e se excluíam mutuamente, e que, entretanto, enquanto aspectos de um mesmo sujeito logicamente diferenciado pela reduplicação, não apenas coexistem, mas formam uma unidade mais rica e mais diferenciada ${ }^{9}$.

Além da validade do Princípio de Não-Contradição - entendido aqui como um dever-ser que governaria o pensar e o falar em todas as suas dimensões - Cirne-Lima trata também da validade do Princípio de Não-Contradição como princípio que, além de reger o pensamento e a fala, regeria também o próprio ser.

Em Hegel, o Princípio de Não-Contradição é entendido e utilizado não apenas como regra lógica, mas também como um princípio que moldaria, de dentro para fora, todos os seres. A dialética hegeliana baseia-se na Lógica, e essa, não seria apenas o fundamento do sistema, mas também o próprio método que, por um lado, conduziria o pensamento em seu trabalho

\footnotetext{
${ }^{9}$ CIRNE-LIMA. Sobre a Contradição. Porto Alegre: Edipucrs, $2^{\mathrm{a}}$ edição, 1996, p. 70.
}

\begin{tabular}{|c|c|l|l|c|c|}
\hline intuitio & $\begin{array}{c}\text { ISSN } \\
1983-4012\end{array}$ & Porto Alegre & Vol.7 $-\mathrm{N}^{\mathrm{o}} .2$ & $\begin{array}{c}\text { Novembro } \\
2014\end{array}$ & p. 184-196 \\
\hline
\end{tabular}


conceitual, enquanto que pelo outro, como princípio interno de organização, estaria dentro de todas as coisas, e assim, as moldaria de dentro para fora em sua estrutura e relações.

A "necessidade absoluta" seria uma categoria sintética na qual necessidade e contingência estariam superadas e guardadas, seria como uma conciliação das extremidades que antes eram opostas.

Para Hegel, além de formas do pensar, conceito e espírito seriam um princípio interno de organização das coisas na história e na natureza. Essa organização do ser e do pensar seria regida pela dialética. Mas como seria possível pensar uma necessidade absoluta que é, ao mesmo tempo, uma contingência absoluta?

Para Cirne-Lima, não existiria uma única lógica modal, mas sim muitos subsistemas lógico-modais diferentes uns dos outros, nos quais o conceito de necessidade, muitas vezes, também possuiria diferentes significados, de tal modo que seria preciso indicar com exatidão de qual subsistema e de qual necessidade se estaria falando. Nesse ponto, Cirne-Lima cita a evolução histórica da Lógica, desde o surgimento dos primeiros operadores modais até o sistema lógico contemporâneo, que seria baseado em apenas dois operadores fundamentais, sendo eles a "possibilidade" e a "necessidade". Entretanto, entre a possibilidade e a necessidade, existiria ainda uma modalidade intermediária, responsável pela mediação entre os juízos possíveis e os estritamente necessários. Ou seja, seria aquele juízo que se referiria a algo real, que é de um determinado modo, mas que igualmente poderia ser de outro. É o que Hegel chamou de contingente.

Atualmente, nos sistemas lógicos formais, se poderia partir tanto da necessidade como da possibilidade, mas jamais da contingência. Essa categoria, que na época de Kant e Hegel era equiparada às outras, hoje seria considerada como algo derivado, uma vez que depende de outra categoria para existir. Dessa forma, Cirne-Lima faz o seguinte questionamento: "Uma tal conclusão não teria severas consequências para a teoria de Hegel sobre a categoria de 'contingência absoluta'?"'

Para resolver essa questão, foram distinguidos três tipos fundamentais de necessidade, sendo elas a "necessidade moral", que seria uma necessidade fraca e que por isso permitiria muitas exceções, a "necessidade natural", própria das leis da natureza, e a "necessidade lógica metafísica" que seria a necessidade das leis lógicas, tão forte a ponto de jamais permitir exceções.

Essa estruturação da necessidade em três níveis é característica de muitos pensadores do final da Idade Média e, de acordo com essa concepção, a Ética, a Filosofia da Natureza e a Lógica seriam como que camadas constituintes do interior de uma mesma Ontologia.

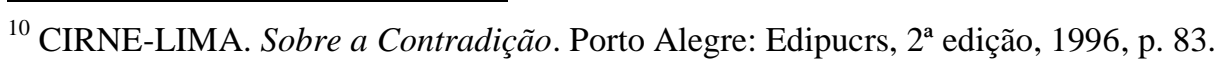

\begin{tabular}{|c|c|l|l|c|c|}
\hline intuitio & $\begin{array}{c}\text { ISSN } \\
1983-4012\end{array}$ & Porto Alegre & Vol.7- $\mathrm{N}^{\circ} .2$ & $\begin{array}{c}\text { Novembro } \\
2014\end{array}$ & p. 184-196 \\
\hline
\end{tabular}




\section{Sobre os níveis estruturais}

Nesse entendimento, o mundo seria apenas o resultado das modificações dessa substância única, e a multiplicidade das coisas seria proveniente de sua necessidade interna. Entrementes, em cada uma dessas três rodadas dialéticas haveria uma estrutura básica que permaneceria sempre a mesma, e se repetiria. Nela, a tese seria sempre a efetividade, enquanto que a antítese seria sempre a possibilidade. Já a passagem para a síntese seria um pouco mais complexa, conforme será abordado na sequência.

Basicamente, a estrutura da argumentação seria a seguinte: a tese representaria a efetividade, a antítese seria a possibilidade, a primeira síntese se referiria à contingência, enquanto que a segunda síntese representaria a necessidade.

Sobre esses níveis estruturais, em suma, Cirne-Lima explica que a tese (efetividade) seria o ser que se refletiria enquanto essência, ou, em outras palavras, seria o ato performativo de pensar.

Sobre isso, Hegel afirma que "o que é efetivo é possível”, já fazendo a introdução para a antítese, visto que o ato performativo através do qual se faz essa afirmação pressuporia desde sempre que ele, já que é e existe, também poderia não ser e existir. Mas para Cirne-Lima, além dessa possibilidade já contida no interior de cada coisa existente (que sempre por igual poderia não existir), haveria também uma outra possibilidade, que ainda não existiria efetivamente, mas que seria possível de haver.

\footnotetext{
A efetividade é ser. Tomamos, aqui, nesta reconstrução como efetividade, apenas o ato performativo que existe em nós, o ato existente, portanto, no qual e pelo qual pensamos e falamos. Esta efetividade existente e que se reflete sobre si mesma é algo que está em processo de movimento. $\mathrm{O}$ ato de pensar movimenta-se, ao pensar, em direção a um fim que ele ainda não captou e que ele ainda não atingiu totalmente ${ }^{11}$.
}

Sob esse prisma, o objetivo em direção ao qual o pensamento se moveria ainda não estaria efetivado, mas, para o pensamento, ele precisaria ser ao menos possível. "O ato performativo de pensar é a tese, a meta que ele ainda não atingiu é a antítese",12.

Assim, o ato performativo de pensar que estaria ainda a meio caminho no processo do pensamento e que anteciparia a totalidade do pensamento completo e acabado, totalmente transparente e presente a si mesmo, seria, por um lado, algo efetivo e, por outro lado, algo possível. Ele seria, assim, tanto efetividade como possibilidade.

\footnotetext{
${ }^{11}$ CIRNE-LIMA. Sobre a Contradição. Porto Alegre: Edipucrs, $2^{\mathrm{a}}$ edição, 1996, p. 92.

${ }^{12}$ CIRNE-LIMA. Sobre a Contradição. Porto Alegre: Edipucrs, $2^{\text {a }}$ edição, 1996, p. 92.
}

\begin{tabular}{|c|c|l|l|c|c|}
\hline intuitio & $\begin{array}{c}\text { ISSN } \\
1983-4012\end{array}$ & Porto Alegre & Vol.7- $\mathrm{N}^{\circ} .2$ & $\begin{array}{c}\text { Novembro } \\
2014\end{array}$ & p. 184-196 \\
\hline
\end{tabular}


Ainda conforme Cirne-Lima, essa seria a segunda síntese entre efetividade e possibilidade, onde estaria contida, como algo superado e guardado, a primeira síntese referente à contingência. Aqui, o termo "superar e guardar" é empregado em seu sentido estrito, onde a contingência, sem se perder e sem ser completamente diluída, foi enviada para um nível mais alto, no qual tem a necessidade como a outra metade de si mesma.

Essas modalidades seriam aspectos diversos da efetividade que, por sua vez, seria una e única, mas que também seria muito vasta em suas diferenciações. "Quando se vê a coisa por esse viés, quando se a vê como uma totalidade que se diferencia em múltiplos aspectos parciais, então não se trata mais da efetividade formal e, sim, da efetividade real"13.

Para Cirne-Lima, a expressão "efetividade real" significa que os diversos aspectos não seriam descritos um a um, mas sim em sua interligação de uns com os outros, sendo todos momentos reais que constituiriam uma mesma e única realidade efetiva. Mas se toda efetividade real é sempre relativa, como fica então a questão do "absoluto" em Hegel?

O núcleo duro dessa argumentação aqui é o mesmo que encontramos no diálogo Parmênides de Platão: se há partes, então necessariamente há um todo do qual as partes são aquilo que são, a saber, partes. Assim também com o relativo. Pode haver coisas relativas; mais ainda, tudo pode ser relativo, exceto este fato e esta constatação de que tudo é relativo. E assim se faz a passagem da efetividade que é real e relativa para a efetividade absoluta ${ }^{14}$.

Em Hegel, deve-se analisar a identidade existente entre os pontos opostos de contingência e necessidade em analogia com a implicação lógica, como a conexão entre um condicionante e o seu condicionado. Contingência e necessidade absolutas seriam duas faces da mesma realidade efetiva, e essa efetividade estaria em um nível superior chamado por ele de "absoluto".

Mas a questão aqui abordada não é referente ao questionamento sobre a existência das coisas concretas, realmente existentes. O que está em questão aqui é que essas coisas, embora elas de fato existam, poderiam por igual não existir.

No sistema hegeliano, mesmo que inicialmente as leis não sejam conhecidas em sua totalidade, uma vez iniciado o processo, tudo estaria precisamente determinado, logo, tudo seria passível de cálculo. Nesse modelo teórico, a necessidade e a contingência absolutas estariam conciliadas e unificadas. Sobre isso, Cirne-Lima faz o seguinte apontamento: "Se em princípio se pode, a partir de um determinado momento - seja ele o big bang atômico, seja qualquer outro ponto na linha do tempo -, calcular exatamente tudo o que virá a seguir, então não há mais espaço para aquilo que chamamos de contingência das coisas e de liberdade do homem" ${ }^{\text {"15. }}$.

\footnotetext{
${ }^{13}$ CIRNE-LIMA. Sobre a Contradição. Porto Alegre: Edipucrs, $2^{\mathrm{a}}$ edição, 1996, p. 96.

${ }^{14}$ CIRNE-LIMA. Sobre a Contradição. Porto Alegre: Edipucrs, $2^{\mathrm{a}}$ edição, 1996, p. 98.

${ }^{15}$ CIRNE-LIMA. Sobre a Contradição. Porto Alegre: Edipucrs, $2^{\text {a }}$ edição, 1996, p. 104.
}

\begin{tabular}{|c|c|l|l|c|c|}
\hline intuitio & $\begin{array}{c}\text { ISSN } \\
1983-4012\end{array}$ & Porto Alegre & Vol.7- $\mathrm{N}^{\mathrm{o}} .2$ & $\begin{array}{c}\text { Novembro } \\
2014\end{array}$ & p. 184-196 \\
\hline
\end{tabular}


De acordo com Cirne-Lima, o sistema dialético hegeliano tenderia para o necessitarismo, no qual a liberdade seria apenas uma necessidade interiorizada, visto que, para Hegel, o que determinaria o sentido da história e da natureza não seriam os indivíduos, mas sim uma razão universal.

\title{
5 Uma proposta de correção
}

É justamente nesse ponto que Cirne-Lima propõe uma correção à dialética hegeliana. Sua proposta é que a necessidade absoluta não seja entendida como um ser-necessário, mas sim como um dever-ser. "Dever-ser é um tipo de necessidade que, por sua estrutura interna, permite e até exige que as coisas possam ser também de outra maneira" ${ }^{\prime 16}$.

Sob essa ótica entende-se que a contingência já estaria contida no dever-ser. As coisas poderiam ser de uma determinada maneira, mas esse dever-ser não impossibilitaria contra fatos, pelo contrário, ele os pressuporia como sendo possíveis.

\begin{abstract}
No curso e na formação do universo, a combinação de ambos os subprincípios, do princípio da unidade - que fundamenta e explica a iteração e a reprodução daquilo que é igual - e do princípio da multiplicidade - que fundamenta e explica a gênese da multiplicidade e da complexidade das coisas e do mundo - obedece à lei mais alta da Lógica e da Ontologia, a saber, à lei de que não devem existir contradições. Quando contradições de fato surgem, então a lei mais alta que rege o universo, que cuida das contradições existentes, manda que estas sejam trabalhadas e superadas, afim de que aos poucos se alcance ou se restabeleça a coerência universal ${ }^{17}$.
\end{abstract}

Já a necessidade absoluta que, para Hegel, dirigiria todo o processo, em Cirne-Lima seria equivalente ao "dever-ser absoluto", que conteria em si tanto a necessidade relativa como também a contingência das coisas.

Em suma, para Cirne-Lima, a transformação gradual de contingência em necessidade que ocorre na dialética hegeliana, conduziria, em sua última consequência, à eliminação do sujeito concreto que existiria contingentemente, aonde o eu concreto e individual seria dissolvido dentro do eu universal e não contingente. "O eu individual é corroído em sua singularidade e acaba sendo absorvido pelo vórtice dialético que é o movimento do conceito e que, em última instância, só deixa ser e existir o que é universal e necessário" ${ }^{\text {"18. }}$.

Seguindo esse raciocínio, a superação da contingência jamais significaria a sua eliminação, pois, a ideia absoluta não seria um ser-necessário do qual a contingência seria excluída, mas sim um dever-ser absoluto, que sempre se concretizaria na facticidade de um ser.

\footnotetext{
${ }^{16}$ CIRNE-LIMA. Sobre a Contradição. Porto Alegre: Edipucrs, $2^{\text {a }}$ edição, 1996, p. 107.

${ }^{17}$ CIRNE-LIMA. Sobre a Contradição. Porto Alegre: Edipucrs, $2^{a}$ edição, 1996, p. 110.

${ }^{18}$ CIRNE-LIMA. Sobre a Contradição. Porto Alegre: Edipucrs, $2^{\text {a }}$ edição, 1996, p. 113.
}

\begin{tabular}{|c|c|l|l|c|c|}
\hline intuitio & $\begin{array}{c}\text { ISSN } \\
1983-4012\end{array}$ & Porto Alegre & Vol.7- $\mathrm{N}^{\mathrm{o}} .2$ & $\begin{array}{c}\text { Novembro } \\
2014\end{array}$ & p. 184-196 \\
\hline
\end{tabular}


Já o espírito absoluto, por um lado, seria algo sustentado pelo ato performativo individual e contingente, e que não se dissolveria no sistema. Por outro lado, ele conteria não apenas as conexões necessárias, mas também todas as coisas contingentes. A primeira contingência presente na constituição do método dialético seria, conforme já explanado, a possibilidade de existência das contradições. Essa seria a primeira perspectiva sob a qual a contingência caracterizaria todo o processo dialético.

Nesse aspecto, o conceito não seria um ser-necessário, mas sim um dever-ser, e o seu desenvolvimento se daria por meio da contingência, onde seria permitida a existência de contradições que, por princípio, não deveriam existir. Assim seria determinada a figuração concreta assumida pelo conceito. Ainda segundo Cirne-Lima, conceitos contrários seriam encontrados, já formados, tanto na linguagem contingente como na realidade histórica, não sendo possível constituir esses conceitos de maneira construtivista. Logo, também não seria possível deduzi-los.

Como antíteses estariam somente em oposição de contrariedade para com a tese, poderia, em muitos casos, haver mais de uma antítese e, por isso, mais de uma síntese. Logo, na elaboração e execução do sistema, não seria possível ter certeza da captação completa de todos os opostos que de fato existiriam na linguagem e na História. "Mesmo que conseguíssemos abranger todos os opostos contingentemente existentes, não teríamos ainda captado todos os opostos realmente possíveis. É por isso que o sistema tem que ser, sempre e em princípio, um sistema aberto" $" 19$.

Dessa forma, não seria possível que a Filosofia se equiparasse ao estatuto de ciência efetiva conforme requerido por Hegel, simplesmente porque ela nunca estaria completa e definitiva. A contingência que, segundo Cirne-Lima, seria uma característica própria da antítese, não seria eliminada no curso do processo como acreditava Hegel, pelo contrário, ela entraria na constituição da própria síntese. Assim, cada síntese dialética teria tanto um momento necessário (a priori), como um momento contingente (a posteriori).

Com isso, Cirne-Lima não estaria questionando a existência de leis mais "fortes", só que, para ele, estas existiriam dentro de uma rede mais ampla, constituída também por leis mais "fracas", onde o momento necessário existiria somente ligado aos momentos contingentes, e ambos constituiriam o desenvolvimento real da liberdade. Da mesma forma, somente ambos constituiriam a sociedade e o estado. Aí, necessidade e contingência se interligariam em uma única realidade que seria, em parte, normativa, e não completamente como defendido por Hegel.

Essa segunda forma de necessidade seria, de acordo com Cirne-Lima, uma característica específica do homem e de sua História onde, os fatos ocorridos obviamente não poderiam ser desfeitos, mas poderiam adquirir outros sentidos, de forma que, inseridos no contexto da razão,

${ }^{19}$ CIRNE-LIMA. Sobre a Contradição. Porto Alegre: Edipucrs, 2a edição, 1996, p.119.

\begin{tabular}{|c|c|l|l|c|c|}
\hline intuitio & $\begin{array}{c}\text { ISSN } \\
1983-4012\end{array}$ & Porto Alegre & Vol.7 $-\mathrm{N}^{\mathrm{o}} .2$ & $\begin{array}{c}\text { Novembro } \\
2014\end{array}$ & p. 184-196 \\
\hline
\end{tabular}


da história e da vida, poderiam, mais do que serem reconhecidos como erros, transformar-se em conhecimento e, com isso, em algo benéfico para os indivíduos.

\section{Referências}

CIRNE-LIMA, Carlos. Depois de Hegel. Caxias do Sul: Editora Educs, 2006. . Sobre a Contradição. Porto Alegre: Edipucrs, $2^{\mathrm{a}}$ edição, 1996.

FILHO, E. S. Introdução ao pensamento dialético. 2ed. São Paulo: Alfa - Ômega, 1991.

HEGEL, GWF. Fenomenologia do Espírito. Rio de Janeiro: Editora Zahar, 2007.

KANT, Immanuel. Crítica da Razão Pura. (Trad :Manuela P. dos Santos, Alexandre F. Morujão) Lisboa: Fundação Caloute Gulbenkian, 2001.

LUFT, Eduardo. As sementes da dúvida. São Paulo: Editora Mandarim, 2001. Para uma crítica interna ao sistema de Hegel. Porto Alegre: EDIPUCRS, 1995.

MENESES, Paulo. Abordagens hegelianas. Rio de Janeiro: Vieira \& Lent, 2006.

PLATÃO. A República. (Trad. M. H. R. Pereira.) Lisboa: Calouste Gulbenkian, 1993.

ROSENFIELD, Denis. Política e liberdade em Hegel. $2^{\mathrm{a} e d . ~ S a ̃ o ~ P a u l o: ~ E d i t o r a ~ A ́ t i c a ~ S . A ., ~} 1995$.

SOARES, Marly Carvalho. Sociedade civil e sociedade política em Hegel. Fortaleza: Editora UECE, 2006.

UTZ, Konrad. O Método dialético de Hegel. In: Veritas, Vol: 50, N: 1 p. 165-185, Porto Alegre: PUCRS, 2005.

WEBER, Thadeu. Hegel, liberdade, estado e história. Petrópolis: Vozes, 1993.

Recebido em: 20/08/2014

Aprovado para publicação em: 29/09/2014

\begin{tabular}{|c|c|l|l|c|c|}
\hline intuitio & $\begin{array}{c}\text { ISSN } \\
1983-4012\end{array}$ & Porto Alegre & Vol.7- $\mathrm{N}^{\circ} .2$ & $\begin{array}{c}\text { Novembro } \\
2014\end{array}$ & p. 184-196 \\
\hline
\end{tabular}

